\title{
Renal obstructive dysplasia: ultrasound diagnosis and therapeutic implications
}

\author{
C.E. Blane ${ }^{1}$, M. Barr ${ }^{2}$, M.A.DiPietro ${ }^{1}$, A.B.Sedman ${ }^{3}$ and D. A. Bloom ${ }^{4}$ \\ ${ }^{1}$ Departments of Radiology, Section of Pediatric Radiology, ${ }^{2,3}$ Pediatrics and Communicable Diseases, ${ }^{2}$ Pathology, Obstetrics, and \\ ${ }^{4}$ Surgery, Pediatric Urology, University of Michigan Medical Center, Ann Arbor, Michigan, USA
}

Received: 13 August 1990; accepted: 3 October 1990

\begin{abstract}
. 57 cases of renal obstructive dysplasia (defined as the abnormal development of nephronic and ductal structures due to in utero obstruction of the urinary tract) were evaluated in terms of sonographic findings, renal and other associated anomalies, and current status of the child. More than one-third of the cases had bilateral disease and although not uniformly fatal bilateral involvement was associated with significant morbidity and mortality. In 12 of the 33 cases with unilateral dysplasia there was an association with contralateral renal problems including ureteropelvic junction obstruction, vesicoureteral reflux and aplasia. Almost one-half of the cases had congenital anomalies, these included VACTERL association, congenital heart disease, cranial abnormalities and gastrointestinal malformations. Fifteen stillborns and 12 of the patients with bilateral involvement and four with unilateral involvement have died. Four patients are on dialysis (two with bilateral involvement and two with unilateral renal obstructive dysplasia). Only one-quarter are otherwise normal. More serious problems are reported in this mixed age population of patients with obstructive renal dysplasia than has been identified in previous studies. Management decisions of the fetus and child must be based on this new age-expanded population.
\end{abstract}

Renal obstructive dysplasia is a nonhereditary developmental renal abnormality of nephronic and ductal structures that can be cortical, medullary, total or partial and is believed to be secondary to early (in utero) obstruction of the urinary tract $[1,2]$. Other terms describing subgroups of this condition include Potter types II and IV renal dysplasia, hypoplastic kidney and the two types of multicystic dysplastic kidney (the classic type with pelvoinfundibular atresia and the hydronephrotic type) $[1,3]$. Until recently renal obstructive dysplasia was most often discovered on investigation of a neonatal abdominal mass [4]. The increased use of sonography in the past ten years has resulted in the increased detection of dysplasia both prenatally and in the neonatal period. Therapeutic decisions for this sonographically identified patient population must adapt to this expanded age distribution [5]. Most recent reports of renal obstructive dysplasia either contain few cases or report larger numbers from a particular population such as fetuses, neonates or those with surgically proven disease $[3,6,7]$. Reports in the literature of bilateral renal obstructive dysplasia and unilateral disease with contralateral renal problems have involved selected patient populations such as fetuses [8-10]. In one paper a number of other associated congenital anomalies were identified in a population of fetuses with bilateral renal obstructive dysplasia [9]. Our combined maternal and child health care referral facility presented us with the opportunity to survey a mixed age population which the available literature, though excellent, does not review.

\section{Patients and methods}

All pediatric patients and fetuses with the suspected diagnosis of renal obstructive dysplasia were collected from the files of Radiology, Pediatrics, Pediatric Urology and Teratology. The records of patients diagnosed since 1980 , the advent of technically good real-time ultrasound, were examined. The study was not limited to histologically proven cases for we believed such a limit would bias the overview to surgical and necropsy cases. However, only those cases which had ultrasound examinations were included. Recognized cases that were excluded using these criteria were fetuses sent for autopsy from outside institutions and two children referred here for dialysis. Unilateral renal obstructive dysplasia can remain silent and those patients who did not come to medical attention are of course not included. Convincing evidence of the diagnosis was obtained from the sonograms, nuclear imaging studies, histology and/or follow-up examinations in all cases. The sonograms were analyzed for size of cysts (less than $1 \mathrm{~cm}$ being small and greater than $1 \mathrm{~cm}$ being large) and hydronephrosis/hydroureter. The clinical records were reviewed to evaluate general health, presence of other anomalies, and renal function. Fetal compressive deformations, such as Potter facies and club feet related to oligohydramnios, were noted but are not included as "other anomalies" in this study.

\section{Results}

Fifty-seven cases were included in the study: 42 liveborn children (age range: birth to 17 years, seven of whom died within a few hours of birth) and 15 stillborns/fetuses. The 
Table 1. Associations found in 42 patients

\begin{tabular}{|c|c|c|c|}
\hline $\begin{array}{l}\text { Involve- } \\
\text { ment }\end{array}$ & Status & $\begin{array}{l}\text { Other } \\
\text { kidney }\end{array}$ & Other problems \\
\hline \multirow[t]{2}{*}{$\begin{array}{l}\text { Bilateral } \\
\text { ODK (14) }\end{array}$} & Dead (12) & $12 \mathrm{ODK}$ & $\begin{array}{l}1 \text { cloacal plate malformation } \\
1 \text { imperforate anus, VACTERL assoc. } \\
1 \text { malrotation of bowel } \\
1 \text { hypothyroid } \\
2 \text { CHD } \\
1 \text { chromosome translocation } \\
5 \text { none }\end{array}$ \\
\hline & Alive (2) & 2 ODK CRF & $\begin{array}{l}1 \text { ambiguous genitalia, no bladder } \\
1 \text { developmentally delayed, } \\
\text { cardiac arrest }\end{array}$ \\
\hline \multirow[t]{5}{*}{$\begin{array}{l}\text { Unilateral } \\
\text { ODK (28) }\end{array}$} & Dead (4) & $\begin{array}{l}\text { Solitary } \\
\text { kidney }\end{array}$ & none \\
\hline & & 3 normal & $\begin{array}{l}2 \text { VACTERL assoc, congenital } \\
\text { hydrocephalus, CHD } \\
1 \text { conotruncal defect, velopalatine } \\
\text { incompetence assoc }\end{array}$ \\
\hline & Alive (24) & $\begin{array}{l}2 \text { CRF } 1 \text { UPJ } \\
\text { 1 PUV } \\
+ \text { reflux }\end{array}$ & none \\
\hline & & 2 UPJ 1 PUV & $\begin{array}{l}1 \text { tracheoesophageal atresia \& fistula, } \\
\text { coloboma } \\
1 \text { VACTERL assoc, imperforate anus, } \\
\text { tethered cord, CHD } \\
3 \text { none } \\
\text { none }\end{array}$ \\
\hline & & 15 normal & $\begin{array}{l}13 \text { none } \\
1 \text { vertebral anomalies \& scoliosis } \\
1 \text { meatal stenosis }\end{array}$ \\
\hline
\end{tabular}

$\widehat{\mathrm{ODK}}=$ obstructive dysplastic kidney; $\mathrm{CRF}=$ chronic renal failure; $\mathrm{UPJ}=$ ureteropelvic junction obstruction; $\mathrm{PUV}=$ posterior urethral valves; $\mathrm{CHD}=$ congenital heart disease $;$ assoc.$=$ association

renal obstructive dysplasia was unilateral in 33 patients and bilateral in 24 . In 17 of the 32 cases $(53 \%$ ) with prenatal ultrasound examinations, the renal problem was identified on the prenatal study though other anomalies and oligohydramnios were recorded in 11 of the 15 cases where the renal problem was not detected. In many of the cases with multiple anomalies only one or two of the problems were identified on the prenatal ultrasound. In two patients the oligohydramnios noted at delivery was not recognized during the pregnancy due to maternal obesity so that no prenatal ultrasound had been requested. Two patients had received no prenatal care.

The stillborns and fetuses were identified on prenatal ultrasound and/or at autopsy. Twelve patients were identified immediately after birth (mass in abdomen 5 , renal dysfunction 3, other anomalies 4). Three other patients were identified within the first week of life (two with abdominal masses and one with renal dysfunction). Ten other patients were identified after the neonatal period. Three were found to have an abdominal mass, two patients presented with urinary tract infection, two patients presented with posterior urethral valves, one patient each presented with undescended testes and right upper quadrant pain, and one patient was referred for ultrasound with vague abdominal pain. In the 57 cases there were $81 \mathrm{kid}$ neys with renal obstructive dysplasia with histologic evaluation in 62 kidneys (18 unilateral and 22 bilateral). The associations are summarized in Tables 1 and 2 .

The stillborns and deceased patients with bilateral renal obstructive dysplasia died of pulmonary hypoplasia or had documented pulmonary hypoplasia at histology, except one child who died of severe renal failure complicated by cytomegalovirus infection. One of the two patients alive with bilateral disease underwent renal transplantation; she continues to grow poorly and has problems associated with renal osteodystrophy. The other survivor with bilateral disease, on chronic dialysis, survived a cardiac arrest but has developmental problems related to his renal disease and previous anoxia.

Thirty-three patients had unilateral disease. In three cases there was a solitary kidney and lethal pulmonary hypoplasia. Another infant had conotruncal defect velopalatine incompetence association with microphthalmia and died following cardiac surgery. Two infants with VACTERL association, congenital hydrocephalus and cardiac disease are deceased. The remaining 24 patients are alive. Two patients are on peritoneal dialysis, one had two failed renal transplants. Twenty-two children of the original 57 cases retrieved are alive and well. Problems in this latter group include fulgurated posterior urethral valves, repaired ureteropelvic junction obstruction, and vesicoureteral reflux re-implanted or on prophylactic antibiotics.

\section{Ultrasound analysis}

Each kidney was characterized by the size and number of cysts it contained. The level of obstruction was clearly documented for 43 of 81 kidneys. Analysis of these 43 includes 28 kidneys that had large cysts (Fig. 1); 16 of these were in cases with proximal obstruction (ureteropelvic junction) and 12 were in cases with distal obstruction (bladder outlet or urethra). Nineteen kidneys with small cysts had distal obstruction (Fig.2) and six had proximal obstruction. Of the 33 cases with unilateral involvement, 24 had large cysts and nine had small cysts. Of the 24 bilateral cases, one case had no cysts, seven had bilateral large cysts, 12 had bilateral small cysts, and four had large cysts on one side and small cysts on the other (Fig.3).

In the three patients with mixed cyst size, the obstruction was distal at the bladder outlet and/or urethra. In one case of bilateral large cysts the obstruction was proximal on one side and at the bladder on the other. Hydronephrosis and hydroureter in the cystic dysplastic kidney were identified in one case each of unilateral large cysts, unilateral small cysts, bilateral large cysts, and and two cases with bilateral small cysts (Fig.4). Either hydronephrosis or hydroureter was seen in cases with unilateral large and small cysts, bilateral large cysts and in discordant bilateral cases. The presence, timing and degree of vesicoureteral reflux on each side in utero can not be evaluated.

\section{Discussion}

Early in utero obstruction of the urinary tract results in varied morphological changes in the kidneys dependent not only on the level and severity of obstruction, but on the timing in gestation and on individual response of the genitourinary system to factors such as vesico-ureteral re- 
Table 2. Associations found in 15 stillborns

\begin{tabular}{lll}
\hline Involvement & Other kidney & Other problems \\
\hline Bilateral & 10 ODK & 1 Melnick-Needles syndrome \\
ODK (10) & & $\begin{array}{l}\text { 3 cloacal plate malformation } \\
1 \text { omphalocele; anal atresia, CHD } \\
1 \text { omphalocele, hydrocephalus } \\
1 \text { anal artresia, single orbit, alobar } \\
\text { holoprosencephaly }\end{array}$ \\
& & 3 none \\
& & 1 CHD \\
& & 1 alobar holoprosencephaly \\
& & 1 omphalocele \\
Unilateral & 2 solitary kidney & 1 Trisomy 18, CHD \\
ODK (5) & 3 normal &
\end{tabular}

ODK =obstructive dysplastic kidney; $C H D=$ congenital heart disease

flux, fistulas to bowel or beyond the urinary obstruction and on other anomalies. The gross pathologic descriptive terminology used to describe the morphologic result of urinary tract obstruction is extensive but we believe can be most usefully combined under the term renal obstructive dysplasia.

This series of patients illustrates the wide spectrum of renal obstructive dysplasia. It includes those discovered in utero and those presenting as infants and children. The eventual outcome for the fetus or child can be seen to depend on two critical factors, 1) the severity of contralateral renal disease which if severe enough results in pulmonary hypoplasia or renal failure and 2) the severity of other associated lethal congenital anomalies or those with significant morbidity. In our cases with bilateral disease or an in- volved solitary kidney, the majority exhibited pulmonary insufficiency and 16 of 24 had major other anomalies. The two surviving children have severe renal failure with all of its associated problems. Thus bilateral disease has a grave prognosis although it is no longer uniformly fatal. Six cases with unilateral renal disease had other anomalies with high morbidity and mortality and did not survive. Two patients are alive but with chronic renal failure due to contralateral renal disease. Six patients with normal renal function are alive but have significant problems in their one functioning kidney. Two of these patients have serious other congenital anomalies. Thus it is not contralateral renal disease alone that influences the final outcome. It is important for the radiologist and sonographer to be aware of this high association of other system congenital anomalies, in particular congenital heart disease and VACTERL association, and to search diligently for them. In only 13 of the 57 cases of renal obstructive dysplasia ( 7 of which have the appearance of classic unilateral multicystic dysplastic type kidneys), are the children otherwise entirely normal.

The sonographic appearances in renal obstructive dysplasia have been described $[3,6,7,11,12]$. It is important to recognize the wide variation in size of the cysts including absence of them, and that the presence of hydronephrosis and hydroureter does not exclude the diagnosis of renal obstructive dysplasia. Though the majority of our cases with small cysts had distal obstruction, large and small cysts occurred in kidneys with either proximal or distal obstruction, differing from a previous report [3]. Since cyst size is not determined by level of obstruction we pos-
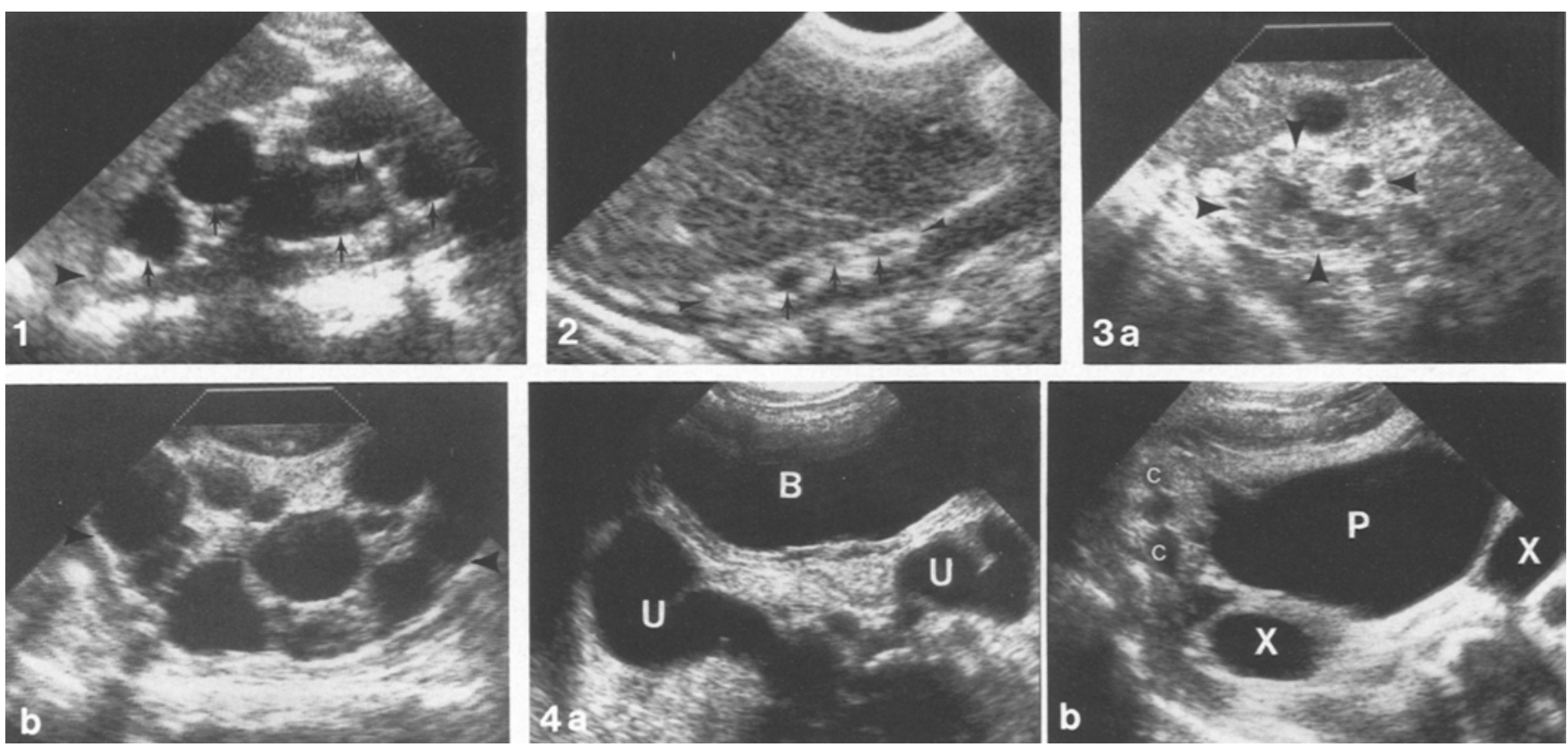

Fig. 1. Longitudinal sonogram of left obstructive dysplastic kidney (arrowheads) in 8-month-old with many large cysts (arrows)

Fig. 2. Longitudinal sonogram of right obstructive dysplastic kidney (arrowheads) in 1-year-old with tiny cysts (arrows)

Fig. 3. a, b Transverse sonogram of right kidney (arrowheads) with small cysts (a) and longitudinal sonogram of left kidney (arrow- heads) with large cysts (b) in newborn with bilateral obstructive dysplasia and urethral stenosis

Fig.4.a Newborn transverse sonogram through the blader (B) demonstrating dilated ureters (U). b Transverse sonogram through the right kidney in the same infant demonstrates dilatation of central pelvis $(\mathrm{P})$, calyces $(\mathrm{C})$ and several cysts $(\mathrm{X})$ 
tulate cyst size may be related to the timing in gestation of the obstruction. We suggest that obstruction early in utero probably results in small cysts, and the later in gestation the obstruction occurs, the larger the cysts. The acutal level of the obstruction does not play a role. However, distal obstructive lesions may embryologically evolve more often early in utero and proximal obstruction may more often be a later embryological event accounting for the high percentage distribution of cyst size and level of obstruction.

The classic unilateral multicystic dysplastic kidney, initially described in 1836 , has been considered a surgical lesion until recently $[4,6]$. However, with the more recent introduction of prenatal sonography, the population of cases under discussion often now includes more than just this classic unilateral multicystic dysplastic kidney. Fetuses as well as neonates and infants with all the variants included in the term renal obstructive dysplasia require consideration. Management decisions now extend beyond whether or not to perform nephrectomy, for consideration must be given to the management of the pregnancy, timing and route of delivery, and support of the neonate, who may be totally asymptomatic or critically ill. Development of criteria for accurate prognosis would be helpful in making these management decisions. Prenatal ultrasound appears to identify two populations of renal obstructive dysplasia. In one group is the infant with unilateral disease and no other renal disease or other congenital anomaly and who in the past would have perhaps come to medical attention for an abdominal mass or urinary tract infection. The second larger group of patients are those with multiple other congenital anomalies and/or bilateral renal disease. Many of these may be stillbirths or have early neonatal death due to pulmonary hypoplasia.

The careful morphological analysis provided by Paille and coauthors emphasizes the spectrum of findings in renal obstructive dysplasia [11]. However, we believe the importance is not in the actual categorization of the sonographic patterns, but in recognition that these varied appearances are part of the spectrum of renal obstructive dysplasia. We believe that prognosis in any one case is determined more by the presence of contralateral renal disease and/or other anomalies than by the size of the cysts or site of obstruction. Thus the radiologist on prenatal ultrasound must look diligently for contralateral renal dis- ease, other anomalies involving the gastrointestinal tract, heart and head in particular, and to identify the presence of oligohydramnios which is correlated with pulmonary hypoplasia.

\section{References}

1. Bernstein J (1971) The morphogenesis of renal parenchymal maldevelopment (renal dysplasia). Pediatr Clin North Am 18: 395

2. Beck AD (1971) The effect of intra-uterine urinary obstruction upon the development of the fetal kidney. J Urol 105: 784

3. Sanders RC, Nussbaum AR, Solez K (1988) Renal dysplasia: sonographic findings. Radiology 167: 623

4. Bloom DA, Brosman S (1978) The multicystic kidney. J Urol 120: 211

5. Gordon AC, Thomas DFM, Arthur RJ, Irving HC (1988) Multicystic dysplastic kidney: Is nephrectomy still appropriate? J Urol 140: 1231

6. Walker D, Fennell R, Garin E, Richard G (1978) Spectrum of multicystic renal dysplasia. Diagnosis and management. Urology 11: 433

7. Glazer GM, Filly RA, Callen PW (1982) The varied sonographic appearance of the urinary tract in the fetus and newborn with urethral obstruction. Radiology 144: 563

8. Kleiner B, Filly RA, Mack L, Callen PW (1986) Multicystic dysplastic kidney: Observations of contralateral disease in the fetal population. Radiology 161:27

9. D'Alton M, Romero R, Grannum P, DePalma L, Jeanty P, Hobbins JC (1986) Antenatal diagnosis of renal anomalies with ultrasound. IV. Bilateral multicystic kidney disease. Am J Obstet Gynecol 154: 532

10. Schifter T, Heller RM (1988) Bilateral multicystic dysplastic kidneys. Pediatr Radiol 18: 242

11. Paille P, Garel L, Grignon A, Allaire G, Simard P, Genier N (1986) Fetal renal dysplasia: Sonographic visualisation of six characteristic patterns with histological correlation. Ann Radiol 29: 406

12. Mahoney BS, Filly RA, Callen PW, Hricak H, Golbus MS, Harrison MR (1984) Fetal renal dysplasia: Sonographic evaluation. Radiology 152:143

C.Blane, M.D.

Pediatric Radiology

University of Michigan Hospitals

C.S. Mott Children's Hospital C3123/0252

200 E. Hospital Drive

Ann Arbor, Michigan 48109-0252

USA 